\title{
Body Size of the Monomorphic Ant Lasius niger: Young Colonies along a Metal Pollution Gradient
}

\author{
Irena M. Grześ, Mateusz Okrutniak, and Gracjan Antosik \\ Department of Environmental Zoology, University of Agriculture in Krakow, Aleja Mickiewicza 24/28, 30-059 Krakow, Poland \\ Correspondence should be addressed to Irena M. Grześ; irena.grzes@ur.krakow.pl
}

Received 15 July 2015; Accepted 20 September 2015

Academic Editor: Jacques Hubert Charles Delabie

Copyright ( 2015 Irena M. Grześ et al. This is an open access article distributed under the Creative Commons Attribution License, which permits unrestricted use, distribution, and reproduction in any medium, provided the original work is properly cited.

\begin{abstract}
Metal pollution may cause the decrease in the individual body size. In ants, the morphological diversity within and between colonies may be much higher than that considered before, even in monomorphic ants. In this study we measured the body size, expressed as head width, of Lasius niger workers collected from 44 young colonies in their ergonomic stage along a well-known gradient exhibiting chronic metal pollution. We calculated statistics describing the body size distribution curve, namely, average, median, data range, skewness, and kurtosis. None of these statistics correlated with the pollution level. Contrary to our previous study performed on mature colonies, workers from young colonies do not display pollution-related morphological changes. The results stress the importance of developmental stage of colony on diversifying body size of the worker cast, in monomorphic ants living in metal-polluted areas.
\end{abstract}

\section{Introduction}

Some social insects have evolved morphologically distinct subcastes of workers, dedicated to different tasks in the colony. However, most ant species and genera maintain a single behaviorally flexible worker cast [1]. Despite being monomorphic, considerable inter- and intracolony worker size variation may exist $[2,3]$. Although such a variation was generally considered to be too small to be relevant for task allocation, the recent study has effectively challenged this claim. Workers of the monomorphic species Temnothorax rugatulus foraging outside the nest might be bigger than intranidal workers [4]. Therefore, monomorphism does not necessarily mean the absence of body size-related division of labour. The question can also be asked as to what extent the body size of monomorphic ants can be modified in polluted and stressed environments. Field studies as well as laboratory experiments showed that in many invertebrate species individual body size may decrease along the metal pollution gradient [5-7]. Significant decreases in body size have also been observed along urbanization gradients $[8,9]$. However, as many other authors indicated, the relationship between body size and urbanization or metal pollution pressure might be much more complex and cannot always be described as simple increase or decrease [10-12].

In our previous studies we analyzed the body size of the monomorphic ant Lasius niger (L., 1758) along a wellknown gradient of metal pollution [13]. We tested body size under the expectation that it will decrease along the increasing metal pollution gradient as a result of toxicity and/or food limitation. We found that the average body size was unrelated to pollution, but the frequency of relatively small ants increased with the pollution level. Thus, the shape of body size distributions seems to respond to environmental stress, although the investigated ant is considered monomorphic [14]. We found similar increase of relatively small ants without a change in the median or average size in related species Lasius flavus (Grześ, Okrutniak unpublished). We proposed a hypothesis that the observed change might be underlined by energetic constraints in the colony. The study on Lasius niger was undertaken on mature colonies, at the reproductive stage, namely, the stage of intensive sexual cast production, that is energetically costly to breed [15]. Therefore, the question appears to be whether the observed change depends on the developmental stage of the colony. 
In the present study we investigated 44 young nests (not producing sexual casts) of Lasius niger located along a well-known pollution gradient, which was the same as the one used in the previous study. The body size (expressed as head width) was measured. We compared the statistics describing the central tendency and distribution shape along the pollution gradient.

\section{Materials and Methods}

2.1. Study Species and Study Area. The black garden ant (Lasius niger) is one of the most common species in the Palearctic area [14]. Our previous study revealed that $L$. niger is the most abundant ant, compared to other species inhabiting the investigated area [16]. The species inhabit various anthropogenic environments like farmlands, pastures, ruderal places, or green spaces in urban areas. L. niger is strictly monogynous and monomorphic, building mineral nest mounds containing from a hundred to more than ten thousand workers. The species of interest is both aphidicolous and carnivorous [14].

The study area is located in the vicinity of Olkusz in Southern Poland. Metal concentrations in the humus layer at the most polluted sites in this region exceed $9600 \mathrm{mg} / \mathrm{kg}$ for zinc, $1500 \mathrm{mg} / \mathrm{kg}$ for lead, and $80 \mathrm{mg} / \mathrm{kg}$ for cadmium [17]. Previous studies performed in the area showed that metal concentrations in the soil are highly correlated with each other [10, 18]. Fifteen study sites were established along the pollution gradient covering abandoned fields and fresh meadows. The transect extended from 0.7 to $35 \mathrm{~km}$ from the pollution source. Metal concentrations at the sites decreased with an increasing distance to the smelter, approaching background levels at the sites further than $25 \mathrm{~km}$ from the smelter. The study sites were represented by abandoned fields (11 sites), mown meadows (1 site), and industrial wastelands (3 sites).

2.2. Pollution Level. In order to provide a biologically realistic measure of the pollution level of each site, we analyzed $\mathrm{Zn}$ and $\mathrm{Cd}$ concentrations in a random sample of invertebrates collected at each site in a preliminary study in the summer of 2011. Zn concentration in invertebrates correlated positively with both the $\mathrm{Cd}$ concentration in invertebrates and the $\mathrm{Zn}$ total soil concentrations. The lowest and highest Zn concentrations in invertebrates accounted for 134 and $1,545 \mathrm{mg} / \mathrm{kg}$ dry weight (d.w.). In turn, the lowest and highest Cd concentrations in invertebrates accounted for 3.98 and $39.70 \mathrm{mg} / \mathrm{kg}$ d.w. The detailed $\mathrm{Zn}$ and Cd concentrations in invertebrates and in the soil samples as well as the botanical description of the study sites are reported in [13] (see sites S1-S3, S5, S6, S8, S10-S12, and S14-S19). Zn concentration in invertebrates was used as an indicator of pollution level.

2.3. Morphological Measurements. The species identification followed [14]. In each of the 15 study sites, 3 young colonies of $L$. niger were selected $(15 \times 3=45)$. One colony was excluded from the final analysis due to the mistake during sampling. All colonies were checked for the absence of sexual casts. A random sample of about $30 \pm 3$ workers from each nest was collected using exhaustor and stored in $-5^{\circ} \mathrm{C}$ till being measured. The body size of ants was expressed as the maximum head width above the eyes (HW) [14]. All measurements of head widths were performed under $50 \mathrm{x}$ magnification using a metallographic microscope Met-153 (Motic, China) connected to a digital camera (Huvitz, Korea). The head widths were measured to the nearest $0.00001 \mathrm{~mm}$ based on digital photos using Panasis, ver. 2.4.2, Huvitz. In order to check the accuracy of the measurements 30 ants were measured twice. The results of the first and the second set of measurements were correlated. High correlation coefficient $(r=0.90, P<0.0001)$ indicated high repeatability of the measurements. In L. niger ants, the nest volume grows almost proportionally to the colony size [19]; therefore, the nest basal area diameter was used as an estimator of the colony size. In all colonies used in this study, the mound diameter ranged from 10 to $47 \mathrm{~cm}$ (median size accounted for $19.0 \mathrm{~cm}$ ).

2.4. Statistical Procedures. To test the relationships between the pollution level and body size of $L$. niger, the descriptive statistics of head width, including mean, median, and range, as well as kurtosis and skewness, were calculated. Each of these statistics was calculated on each colony and was correlated separately with the pollution levels of the sites ( $\mathrm{Zn}$ concentration in the invertebrates). The significance of each relationship was tested using a simple regression (Statgraphics Centurion XV) with a 95\% confidence level followed by a check for normality of residuals. In ants the body size can be correlated with the size of colony [20-22]. Therefore, in order to eliminate the influence of the colony size prior to correlating with the pollution level, each statistic was first correlated with the colony size. The residuals were then regressed against the pollution level. Thus, when testing the relationship between head size and pollution, only the fraction of variance that was not explained by the colony size was used. As three ant nests were collected at each site, the values of residuals for each of the statistics were averaged to avoid a problem of pseudoreplication [23].

\section{Results}

The average head size ranged between 700 and $965 \mu \mathrm{m}$. The head size differs significantly between colonies (oneway ANOVA, $F=35.52, P<0.0001$; Figure 1$)$. The size distribution in each colony did not depart significantly from the normal distribution as both st. skewness and st. kurtosis were within the range expected for normal distribution -2 to +2 . No statistics (average, median, range, st. skewness, and st. kurtosis) correlated significantly with pollution of the site $(P>0.05$ in each case, Table 1$)$.

\section{Discussion}

The aim of this study was to test if the bias towards the higher frequency of small ants, detected in previous studies in mature colonies of Lasius niger, occurs also in the younger colonies of this species. Based on our study no significant 
TABLE 1: The results of linear regression of statistics describing the body size distribution of Lasius niger workers versus pollution level. Five independent analyses were done. None of the statistics were significantly correlated with the metal pollution gradient.

\begin{tabular}{lcccc}
\hline Statistics & $F$ & $R^{2}$ & $P$ & Interpretation \\
\hline Average & 0.91 & 0.065 & 0.56 & Central tendency measurements are independent of the pollution levels of the sites. \\
Median & 0.81 & 0.059 & 0.38 & \\
\hline Range & 2.99 & 0.187 & 0.11 & The range of dispersal of body size per site is not dependent on the pollution levels of the sites. \\
\hline st. skewness & 0.19 & 0.147 & 0.67 & The distribution shape is independent of the pollution levels of the sites. \\
st. kurtosis & 0.99 & 0.071 & 0.34 & \\
\hline
\end{tabular}

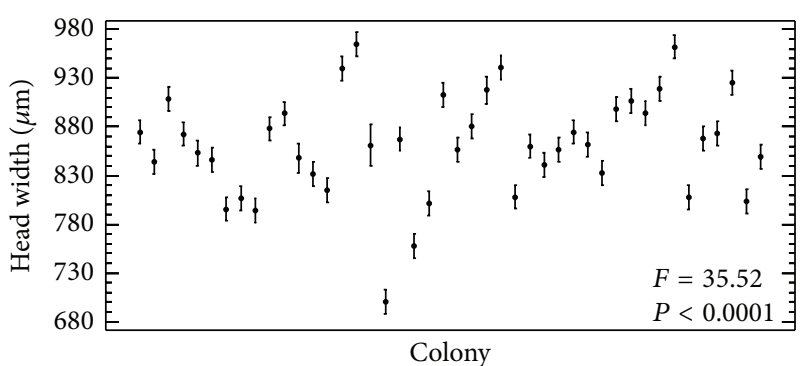

Figure 1: The results of one-way ANOVA of head size of the ant Lasius niger collected from 44 colonies. Points represent the mean value calculated per colony. Whiskers denote $95 \%$ intervals of LSD test. Since $P<0.0001$, the colonies differ significantly in average head size of workers.

increase of the fraction of small ants was found along the pollution gradient. In turn, big and mature colonies were found previously to contain larger fraction of small workers along the increasing metal pollution gradient. Thus, the change in the shape of body size distribution in the investigated ant seems to be associated with the developmental stage of the colony. In both previous and present study we used the same species, study area, measurement procedures, and a similar number of colonies $\left(N_{\text {mature }}=51, N_{\text {young }}=44\right)$ and identical number of individuals per colony $\left(N^{=} 30\right)$. Therefore, we believe that the comparison between mature and young colonies in the study should be mandatory.

Trace metal pollution is known to cause a range of toxic effects on invertebrates [24-27]. Considering the effects on morphology, metal pollution may induce morphological deformities [28], the increase in developmental instability $[29,30]$, and reduced body size $[6,31]$. Generally, three mechanisms may underline the negative impact of metals on the body size/mass: (1) toxicity of metals based on the displacement of the essential metals from enzymes at active sites, resulting in loss of their function, (2) trade-offs between the cost of detoxication and energy allocation to growth and development $[6,32]$, and (3) limited food availability in contaminated areas [7]. In this study we conclude that L. niger may undergo certain morphological changes along the pollution gradient, but the change seems to be associated with mature colonies but not with young colonies. This observation might be explained in the light of the colony development and energy allocation within the colony.

In ants, three main phases of colony development over its lifespan can be distinguished [33]. The first phase called "colony founding" is characterized by the absence of adult workers; the only adult present is the egg lying queen. The development of the colony at this stage is weakly dependent on external food resources but remains heavily reliant on the amount of fat accumulated in the queen. The moment of transition to the next stage of colony development, namely, the ergonomic stage, is eclosion of the first workers. At this stage the queen is focused exclusively on egg lying, while the workers are concerned with brood care. As a consequence, at this stage the energy investments in the colony are devoted to colony growth rather than reproduction or dispersal. When the number of adult workers approaches a certain level, the production of the virgin queens and males starts; thereby the colony enters the reproductive stage. Therefore, young colonies allocate their resources to rearing workers, thus facilitating colony growth, while mature colonies have to share the energy to be allocated between a new generation of workers and in sexual castes. Rearing males and females in mature colonies that are at the reproductive stage most likely needs more effort than simply rearing workers in the young colonies at the same reproductive stage. Tschinkel observed that workers of the Pogonomyrmex ants lose 20\% fat during the male and female feeding phase that takes place in July [34]. Therefore, the increased fraction of small workers observed in mature colonies, but not in young colonies, might be an effect of energy limitation during intensive production of sexuals.

\section{Conclusions}

We did not find the pollution-related increase of the fraction of relatively small workers in the young colonies of $L$. niger to be similar to that found in the previous analogical research performed on the mature colonies. The results of this study suggest that body size in monomorphic ant Lasius niger may undergo shifts in the distribution of the body size as a result of the interaction of metal pollution and the stage of the colony development. Energetic constraints during the sexual casts rearing might explain the proved difference between young and mature colonies.

\section{Conflict of Interests}

The authors declare that there is no conflict of interests regarding the publication of this paper. 


\section{Acknowledgment}

This study was supported by The National Science Centre (NCN), based on decision DEC- 2011/01/D/NZ8/00167.

\section{References}

[1] B. Holldobler and E. O. Wilson, The Ants, Belknap Press, Cambridge, UK; Harvard University Press, Cambridge, Mass, USA, 1990.

[2] K. O. Laskis and W. R. Tschinkel, "The seasonal natural history of the ant, Dolichoderus mariae, in northern Florida," Journal of Insect Science, vol. 9, no. 2, pp. 1-26, 2009.

[3] E. J. Gouws, K. J. Gaston, and S. L. Chown, "Intraspecific body size frequency distributions of insects," PLoS ONE, vol. 6, no. 3, Article ID e16606, 8 pages, 2011.

[4] J. N. Westling, K. Harrington, S. Bengston, and A. Dornhaus, "Morphological differences between extranidal and intranidal workers in the ant Temnothorax rugatulus, but no effect of body size on foraging distance," Insectes Sociaux, vol. 61, no. 4, pp. 367-369, 2014.

[5] M. E. Abdl-Hamed, M. R. Tolba, and J. H. Lashin, "Effect of water quality on the fecundity and body size of Sphaeroma serratum (Crustacea: Isopoda)," Journal of King Abdulaziz University-Science, vol. 3, no. 1, pp. 101-111, 1991.

[6] M. Maryański, P. Kramarz, R. Laskowski, and M. Niklińska, "Decreased energetic reserves, morphological changes and accumulation of metals in carabid beetles (Poecilus cupreus L.) exposed to Zinc- or Cadmium-contaminated food," Ecotoxicology, vol. 11, no. 2, pp. 127-139, 2002.

[7] M. Lagisz, "Changes in morphology of the ground beetle Pterostichus oblongopunctatus F. (Coleoptera; Carabidae) from vicinities of a zinc and lead smelter," Environmental Toxicology and Chemistry, vol. 27, no. 8, pp. 1744-1747, 2008.

[8] V. V. Naidenko and O. M. Grechkanev, "Biota elements state as the indicator of natural systems disturbance in oil production," Ecology, vol. 1, pp. 67-69, 2002 (Russian).

[9] G. A. Timofeeva and N. I. Savosin, "Some aspects of fauna and population structure in ground beetles of Kemerovo and its suburbs," in Mordovia University Articles, Mordovia University, Saransk, Russia, pp. 69-70, 2009 (Russian).

[10] P. M. S. Zygmunt, M. Maryański, and R. Laskowski, "Body mass and caloric value of the ground beetle (Pterostichus oblongopunctatus) (Coleoptera, Carabidae) along a gradient of heavy metal pollution," Environmental Toxicology and Chemistry, vol. 25, no. 10 , pp. 2709-2714, 2006.

[11] T. Magura, B. Tóthmérész, and G. L. Lövei, "Body size inequality of carabids along an urbanisation gradient," Basic and Applied Ecology, vol. 7, no. 5, pp. 472-482, 2006.

[12] R. Sukhodolskaya, "Intraspecific body size variation in ground beetles (Coleoptera, Carabidae) in urban-suburban-ruralnatural gradient," Acta Biologica Universitatis Daugavpiliensis, vol. 13, no. 1, pp. 121-128, 2013.

[13] I. M. Grześ, M. Okrutniak, and M. W. Woch, "Monomorphic ants undergo within-colony morphological changes along the metal-pollution gradient," Environmental Science and Pollution Research, vol. 22, no. 8, pp. 6126-6134, 2015.

[14] W. Czechowski, A. Radchenko, W. Czechowska, and K. Vepsäläinen, The Ants of Poland with Reference to the Myrmecofauna of Europe, Museum and Institute of Zoology, Polish Academy of Sciences, Natura Optima dux Foundation, Warszawa, Poland, 2012.
[15] J. J. Boomsma and J. A. Isaaks, "Energy investment and respiration in queens and males of Lasius niger (Hymenoptera, Formicidae)," Behavioral Ecology and Sociobiology, vol. 18, no. 1, pp. 19-27, 1985.

[16] I. M. Grześ, "Ant species richness and evenness increase along a metal pollution gradient in the Bolesław zinc smelter area," Pedobiologia, vol. 53, no. 1, pp. 65-73, 2009.

[17] D. Stone, P. Jepson, P. Kramarz, and R. Laskowski, “Time to death response in carabid beetles exposed to multiple stressors along a gradient of heavy metal pollution," Environmental Pollution, vol. 113, no. 2, pp. 239-244, 2001.

[18] A. M. Stefanowicz, M. W. Woch, and P. Kapusta, "Inconspicuous waste heaps left by historical $\mathrm{Zn}-\mathrm{Pb}$ mining are hot spots of soil contamination," Geoderma, vol. 235-236, pp. 1-8, 2014.

[19] P. Rasse and J. L. Deneubourg, "Dynamics of nest excavation and nest size regulation of Lasius niger (Hymenoptera: Formicidae)," Journal of Insect Behavior, vol. 14, no. 4, pp. 433-449, 2001.

[20] M. V. Brian, "The growth and development of colonies of the ant Myrmica," Insectes Sociaux, vol. 4, no. 3, pp. 177-190, 1957.

[21] B. Gray, "A morphometric study of the ant species, Myrmecia dispar (Clark) (Hymenoptera: Formicidæ)," Insectes Sociaux, vol. 18, no. 2, pp. 95-109, 1971.

[22] W. R. Tschinkel, "Colony growth and the ontogeny of worker polymorphism in the fire ant, Solenopsis invicta," Behavioral Ecology and Sociobiology, vol. 22, no. 2, pp. 103-115, 1988.

[23] S. H. Hurlbert, "Pseudoreplication and the design of ecological field experiments," Ecological Monographs, vol. 54, no. 2, pp. 187-211, 1984.

[24] M. B. Pedersen, J. A. Axelsen, B. Strandberg, J. Jensen, and M. J. Attrill, "The impact of a copper gradient on a microarthropod field community," Ecotoxicology, vol. 8, no. 6, pp. 467-483, 1999.

[25] A. Heikens, W. J. G. M. Peijnenburg, and A. J. Hendriks, "Bioaccumulation of heavy metals in terrestrial invertebrates," Environmental Pollution, vol. 113, no. 3, pp. 385-393, 2001.

[26] D. Peplow and R. Edmonds, "The effects of mine waste contamination at multiple levels of biological organization," Ecological Engineering, vol. 24, no. 1-2, pp. 101-119, 2005.

[27] P. S. Rainbow, "Trace metal bioaccumulation: models, metabolic availability and toxicity," Environment International, vol. 33, no. 4, pp. 576-582, 2007.

[28] R. M. Raina, P. Pawar, and R. N. Sharma, "Developmental inhibition and reproductive potential impairment in Musca domestica L. by heavy metals," Indian Journal of Experimental Biology, vol. 39, no. 1, pp. 78-81, 2001.

[29] G. W. C. Ho, K. M. Y. Leung, D. L. Lajus, J. S. S. Ng, and B. K. K. Chan, "Fluctuating asymmetry of Amphibalanus (Balanus) amphitrite (Cirripedia: Thoracica) in association with shore height and metal pollution," Hydrobiologia, vol. 621, no. 1, pp. 21-32, 2009.

[30] S. A. Al-Shami, M. R. C. Salmah, A. A. Hassan, and M. N. S. Azizah, "Fluctuating asymmetry of Chironomus spp. (Diptera: Chironomidae) larvae in association with water quality and metal pollution in Permatang Rawa River in the Juru River Basin, Penang, Malaysia," Water, Air, \& Soil Pollution, vol. 216, no. 1-4, pp. 203-216, 2011.

[31] T. van Ooik, M. J. Rantala, and I. Saloniemi, "Diet-mediated effects of heavy metal pollution on growth and immune response in the geometrid moth Epirrita autumnata," Environmental Pollution, vol. 145, no. 1, pp. 348-354, 2007. 
[32] R. M. Sibly and P. Calow, "A life-cycle theory of responses to stress," Biological Journal of the Linnean Society, vol. 37, no. 1-2, pp. 101-116, 1989.

[33] G. F. Oster and O. E. Wilson, "Colony life cycles," in Caste and Ecology in the Social Insects, G. F. Oster and O. E. Wilson, Eds., pp. 26-74, Princeton University Press, 1978.

[34] W. R. Tschinkel, "Sociometry and sociogenesis of colonies of the harvester ant, Pogonomyrmex badius: worker characteristics in relation to colony size and season," Insectes Sociaux, vol. 45, no. 4, pp. 385-410, 1998. 

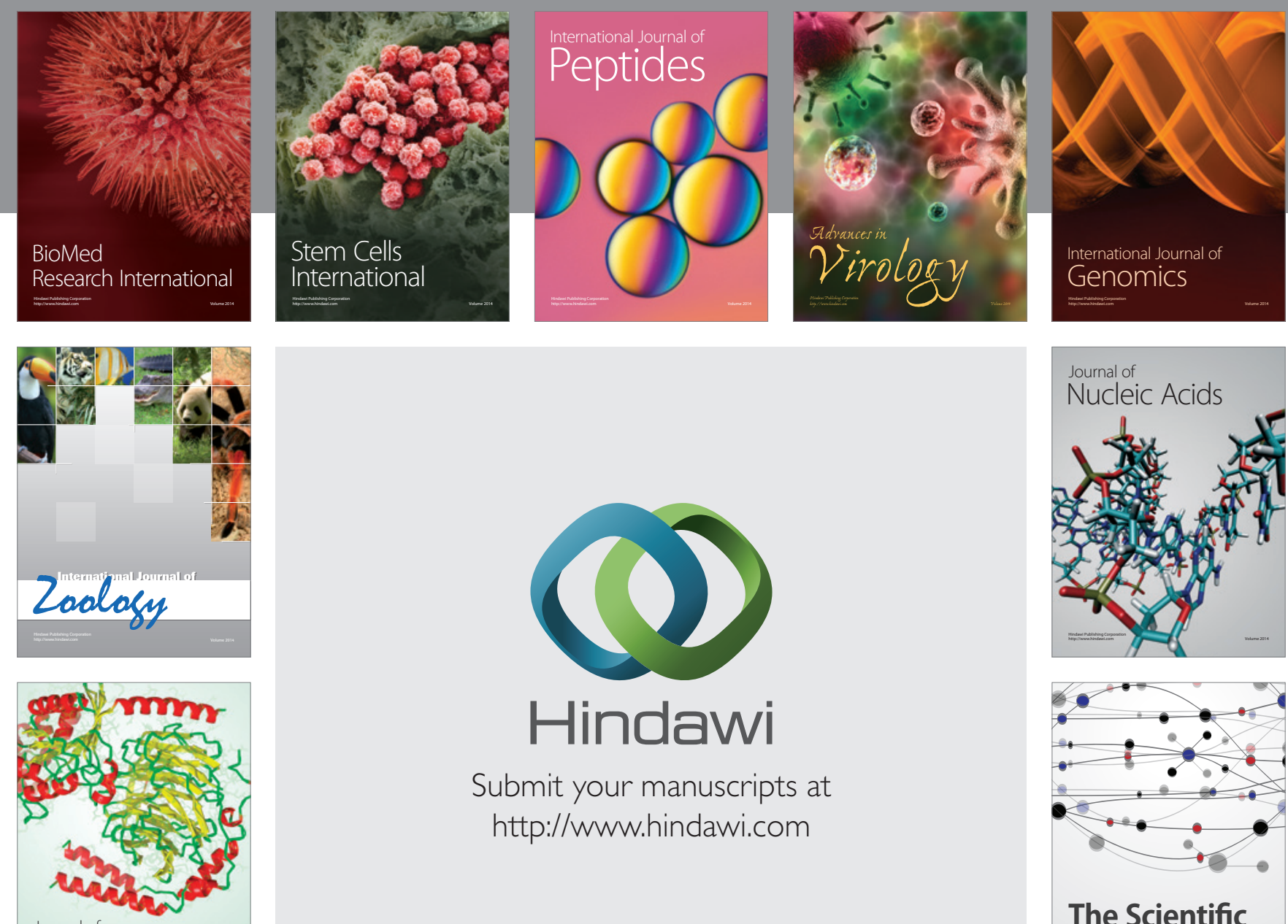

Submit your manuscripts at

http://www.hindawi.com

Journal of
Signal Transduction
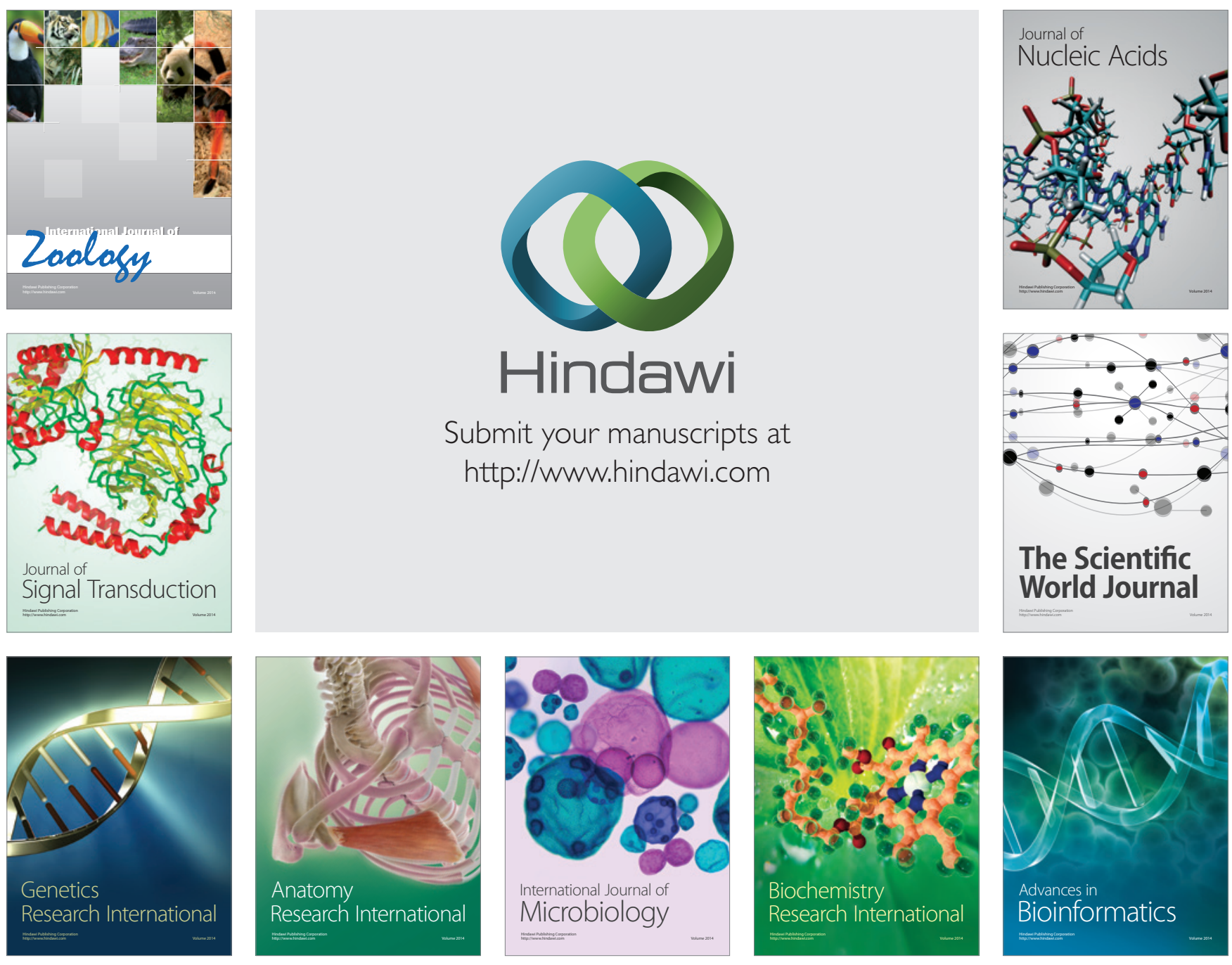

The Scientific World Journal
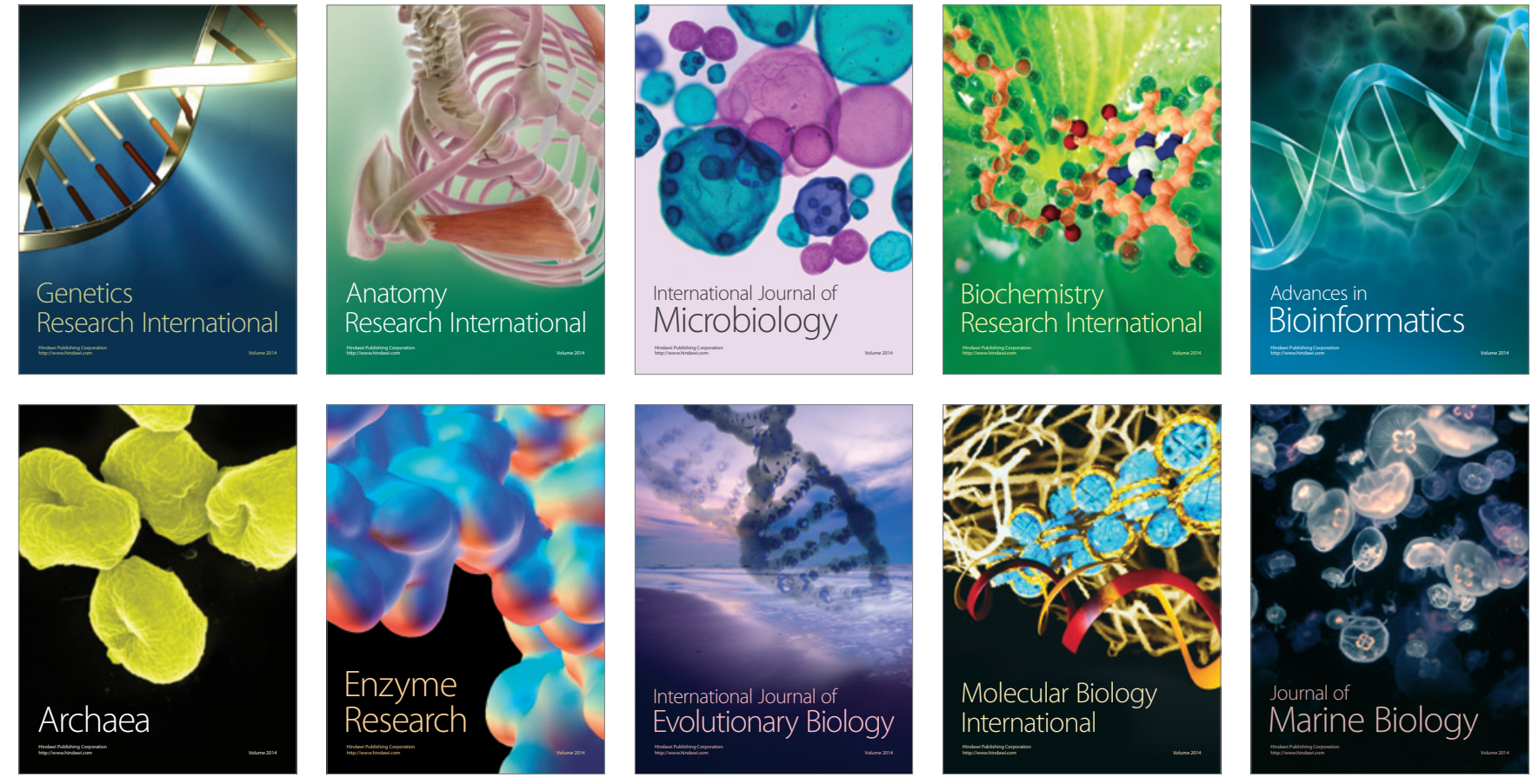